\section{COMPARISON OF APGAR SCORES AND NEONATAL UMBILICAL ARTERIAL BLOOD GASES BETWEEN PREECLAMPSIA AND NORMAL PREGNANCIES}

E. Ouladsahebmadarek ${ }^{1}$, N. Najati ${ }^{2}$, M. Seidhejazie ${ }^{2}$, M. Sayyah-Melli²

${ }^{1}$ Women's Reproductive Health Reasearch Center/ Tabriz University of Medical Sciences, ${ }^{2}$ Tabriz University of Medical Sciences, Tabriz, Iran

Introduction: Preeclampsia is the main cause of maternal mortality, immature neonatal birth and perinatal death. Measurement of umbilical arterial blood $\mathrm{PH}$ has been widely adopted as an adjunct to the Apgar score for assessing the condition of newborn infants.

Aim: To study the Apgar scores and umbilical artery blood gases in neonates born from mothers with and without preeclampsia.

Methods: In a case-control study from 2008 to 2009, one hundred and forty women with preeclampsia and 140 with normal pregnancy were studied at Alzahra teaching hospital. Umbilical artery blood gases from clamped parts of umbilical cords were detected.

Results: The averages of $1 \mathrm{st}$ min and 5th min Apgar scores in case group were $5.2 \pm 1.8 \& 7.7 \pm 1.7$ versus $8.4 \pm 0.8$ \& $9.8 \pm 0.1$ in control group respectively $(p<0.001)$. The mean umbilical arterial blood $\mathrm{PH}$ in case group was $7.08 \pm 0.08$ and $7.35 \pm 0.05$ in other group ( $p<0.001)$. Prevalence of IUGR, seizure, sepsis, hyaline membrane disease and IVH were significantly higher in neonates born from preeclamptic mothers $(p<0.001)$.

Conclusion: None of Umbilical arterial blood gases and Apgar scores alone had the ability to predict the condition of the neonates perfectly but together they had more efficacy.

\section{EFFECT OF LENGTH, FLOW RATE, AND CONCENTRATION OF INFUSATE ON DELIVERY PRESSURES IN 1FR AND 2FR NEONATAL PICC LINES}

W.B. D'Costa, M. Goggin, G.J. Richards

Neonatal Unit, St. George's Heathcare NHS Trust, London, UK

Background/aims: Neonatal infusion pumps are pressure limited. On our NICU, normally functioning 1Frlines frequently exceed maximum pressure limits, and are either removed or flow rates reduced.

We aimed to measure pressures in neonatal PICC lines with varying flow rates and to determine the effect of reduction in length of catheter.

Methods: We infused increasing concentrations of dextrose and TPN \pm lipid through standard $20 \mathrm{~cm}$ length $1 \mathrm{Fr}$ ( Premicath, Vygon) and $30 \mathrm{~cm} 2 \mathrm{Fr}$ ( Nutriline, Vygon) PICC lines at different rates from $1-10 \mathrm{ml} / \mathrm{hr}$. Premicath lines with and without stylet were tested at lengths of $20 \mathrm{~cm}$ and $10 \mathrm{~cm}$. Flowpressure relationships were determined using pressure monitoring infusion pumps (IVAC).

Results: Pressures generated in the 2Fr neonatal lines were significantly lower than those generated through $1 \mathrm{Fr}$ neonatal Premicath lines. Pressure recordings were similar between Premicath lines with and without stylet. Reduction in catheter length did produce a reduction in pressures generated especially at higher flow rates.

Pressures exceeded the standard pressure limit on our unit $(150 \mathrm{mmHg})$ at flow rates of approximately $6 \mathrm{mls} / \mathrm{hr}$.

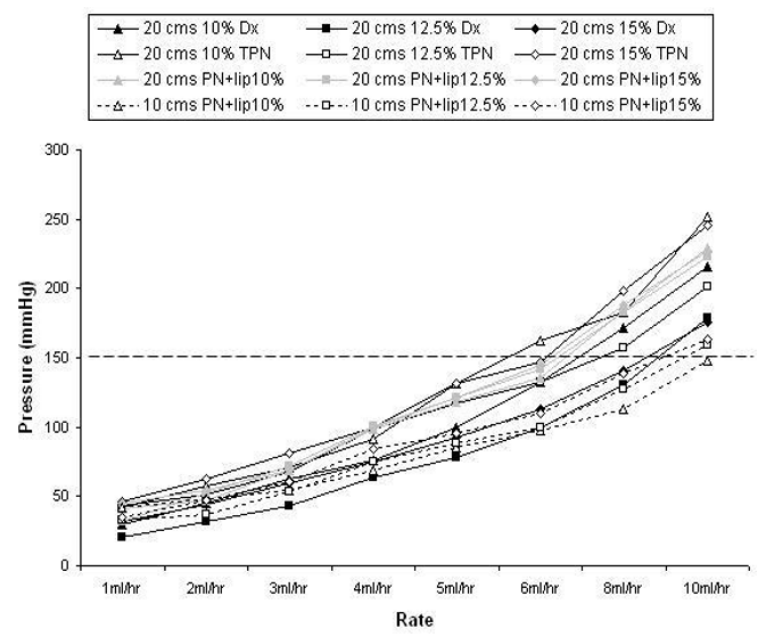

[Flow Pressure Graph for 1Fr PICC lines] 
Conclusions: $1 \mathrm{Fr}$ lines generated far greater pressures than $2 \mathrm{Fr}$ lines to achieve the same flow rate, as predicted from Poiseuille's Law - Flow $\propto$ (Pressure $x$ Radius $^{4}$ )/ (Viscosity $x$ Length).

Reduction in length allowed higher flow rates before pressure limits were reached. Increasing pressure limits above $150 \mathrm{mmHg}$, or reducing line length are the only options available to allow use of these lines at higher flow rates.

\section{3}

\section{IMPACT OF BABIES BORN TO SUBSTANCE MISUSING MOTHERS ON A REGIONAL MATERNITY HOSPITAL IN THE WEST MIDLANDS}

\author{
V.K. Venkatesh, V. Rasiah \\ Neonatology, Birmingham Women's Foundation \\ NHS Trust, Birmingham, UK
}

Background: The incidence of maternal drug misuse is increasing. A screening study found that $16 \%$ of pregnant women in the UK have misused drugs or illicit substances. ${ }^{1}$ The babies born to substance misusing mothers have additional impact on the maternity and neonatal services.

Aim: To review the impact of babies born to substance misusing mothers (SMM).

Methods: A retrospective audit of the care provided to infants born to SMM at a regional maternity hospital in UK over 12 months (01/04/09-31/03/10).

Results: In the last 12 months, 38 babies born to SMM were admitted to the transitional care and 3 were admitted to the neonatal unit because of their prematurity. 31 mothers were on the methadone programme. Their median gestation age was 38 weeks with a median birth weight of 2770 grams. All babies were observed using the modified Finnegan score. 8/41(19\%) needed treatment with morphine. The overall median length of stay (LOS) was 9 days. In those infants who did not need treatment, median LOS was 7.5 days. 16/41 (39\%) had safeguarding issues with 12 infants placed in foster care and 3 infants placed in a mother and baby residential unit.

Conclusion: Babies born to SMM take up significant time, input and resources from the neonatal and social services. They have significantly longer LOS even when they do not need treatment. In view of the increasing prevalence of SMM, this needs to be taken into consideration when allocating resources.

Ref: 1. Eur J Pediatr (1999) 158: 488 - 492

1154

\section{CALCULATING THE COST OF SHORT STAY REFERRALS TO A NEONATAL UNIT}

P. Muthukumar, E. Scott, A. Curley

Neonatal Unit, Cambridge University Hospital NHS Foundation Trust, Cambridge, UK

Background: Additional special care workload includes provision of short stay intervention and management not exceeding 6 hours to any baby born in our hospital. This work does not attract additional funding and is not factored into current staffing levels in our unit.

Objectives: To assess extra cost and staffing time per week for this additional work load.

Methods: Retrospective review of short stay referrals (August - September 2008). assessing reason for referral, duration of stay and background nursing staff ratio using the hospital computer system and admission register.

Results: 89 babies fulfilled the short stay criteria. Median duration of stay was 3628 minutes (7.5 hours/week). The times of referral peaked between $12: 00$ and 24:00h. Common reasons were partial septic screen in $34 \%$, administration of antibiotics in $20 \%$, insertion of peripheral venous line in $9 \%$. The average duration of stay was 30 minutes (IQR 20 - 35). The background nursing staff to baby ratios during the 2 months were 1:3-1:3.5.

Conclusions: The background nursing ratio during the 2 months fell below the BAPM standard for special care. Short stay referrals added an additional burden of 7.5 hours/week of nursing time equating to a cost of $£ 78-£ 150$. Interesting observations were that the peak times were predictable. We conclude there is definite role for a dedicated nurse for short stay babies or enhanced nurse practitioners who could undertake doctor/nurse roles, balance the staff to baby ratio and ultimately lead to seamless care of these babies. 